\title{
Nanoparticles as Depressurization and Augmented Injection Agents to Facilitate Low Permeability Reservoir Exploitation: Potentials and Risks
}

\author{
Jiating Chen ${ }^{1 \dagger}$, Xun Zhong ${ }^{1,2 * t}$ and Fangzhou $\mathrm{Xu}^{1 \dagger}$ \\ ${ }^{1}$ College of Petroleum Engineering, Yangtze University, Wuhan, China, ${ }^{2}$ Key Laboratory of Drilling and Production Engineering for \\ Oil and Gas, Wuhan, China
}

Keywords: depressurization and augmented injection, low permeability, potentials, nanoparticles, risks

\section{INTRODUCTION}

OPEN ACCESS

Edited by:

Qi Zhang,

China University of Geosciences

Wuhan, China

Reviewed by:

Xuyang Tian,

Missouri University of Science and

Technology, United States

Xueling Song,

University of North Dakota

United States

*Correspondence:

Xun Zhong

zhongxun@yangtze.edu.cn

${ }^{\text {t}}$ These authors have contributed equally to this work

Specialty section:

This article was submitted to Advanced Clean Fuel Technologies, a section of the journal Frontiers in Energy Research

Received: 07 December 2021

Accepted: 03 January 2022

Published: 03 February 2022

Citation:

Chen J, Zhong $X$ and Xu F (2022) Nanoparticles as Depressurization and Augmented Injection Agents to Facilitate Low Permeability Reservoir Exploitation: Potentials and Risks.

Front. Energy Res. 10:830742.

doi: 10.3389/fenrg.2022.830742
According to the recent report released by International Energy Agency (IEA), the global demand for energy would increase by $4.6 \%$ in year 2021 . The proportion of proved low permeability oil/gas in total annual proved reserves is now around $70.0 \%$, but the current average recovery is just $23.3 \%$. Since the steady oil production could not be ensured in most mature reservoirs, effective development of low permeability reservoirs becomes the mainstay to mitigate the great gap between energy supply and consumption and also to ensure the national energy security ( $\mathrm{Hu}$ et al., 2018; Xu et al., 2019; Li et al., 2021). Water flooding is the most popular energy supplement technology. However, due to the nature of narrow throats, poor connectivity, high clay content, etc., low-permeability reservoirs usually exhibit high injection pressure and insufficient injection volume. Traditional depressurization and augmented injection technologies such as acidizing/fracturing (Wang et al., 1999; Al-Harbi et al., 2006), surfactant and membrane technology (Qu et al., 2012) are either with short validity or complicate process design, The advances in nanoscience offer a new insight to mitigate the problems confronted with water injection in low/ultra-low permeability reservoirs.

Nanoparticles (NPs) are nanosized (1-100 nm) particles with high surface area, strong interfacial effect and prominent adsorption ability. According to Roco (2011a, 2011b), the overall market value of products concerning nanotechnology was about three trillion dollars by the year 2020. NPs are good depressurization and augmented injection agents with huge potential. This report reviews the opportunities and challenges of using NPs for depressurization and augmented injection based on what has been accomplished in both lab and the field. The driving forces and the influential factors that affect NP performance are analyzed to accelerate NPs selection, as shown in Figure 1. At last, the potential risks and possible solutions encountered by NPs are also discussed.

\section{FUNCTIONAL MECHANISMS}

After long-time water washing and immersion, the porous media surround the wellbore become more water-wet, resulting in thicker water films and narrower water flowing paths. NPs function through multiple mechanisms. The admitted ones include,

Wettability Alteration and Slip Effect: Hydrophobic NPs can form stable hydrophobic films on pore surfaces, replace the hydration layer, expand the flowable path, increase water relative permeability and decrease the flow resistance, thereafter, the high injection pressure problem can be resolved (Wang et al., 2018). Furthermore, hydrophobic surfaces demonstrate impressive 
A

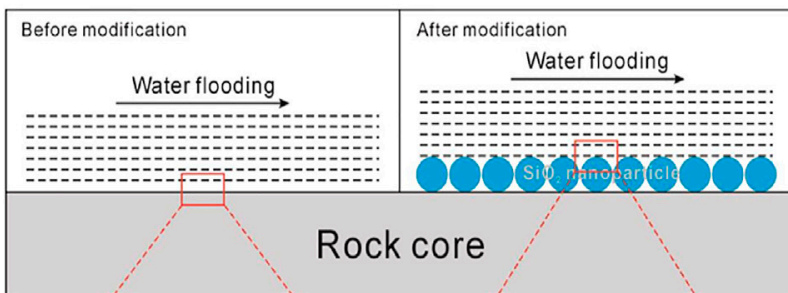

(a)

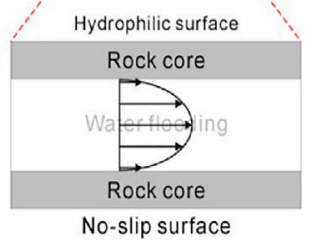

(b)

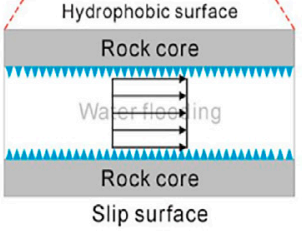

Slip surface

\section{B}

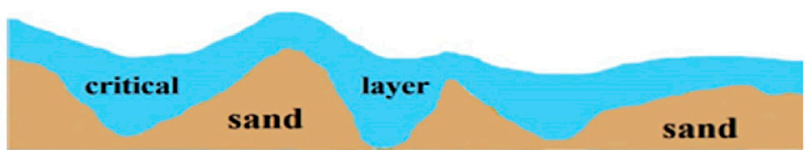

hydrophilic silica
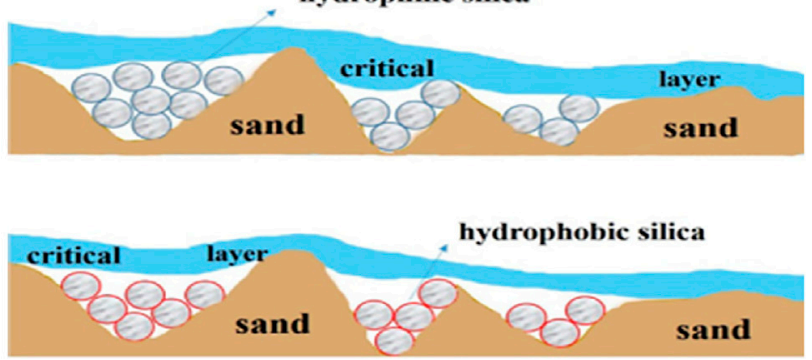

Surface Roughness Reduction

C

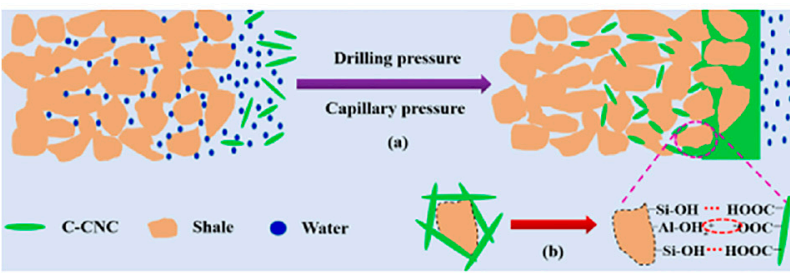

Slip Effect

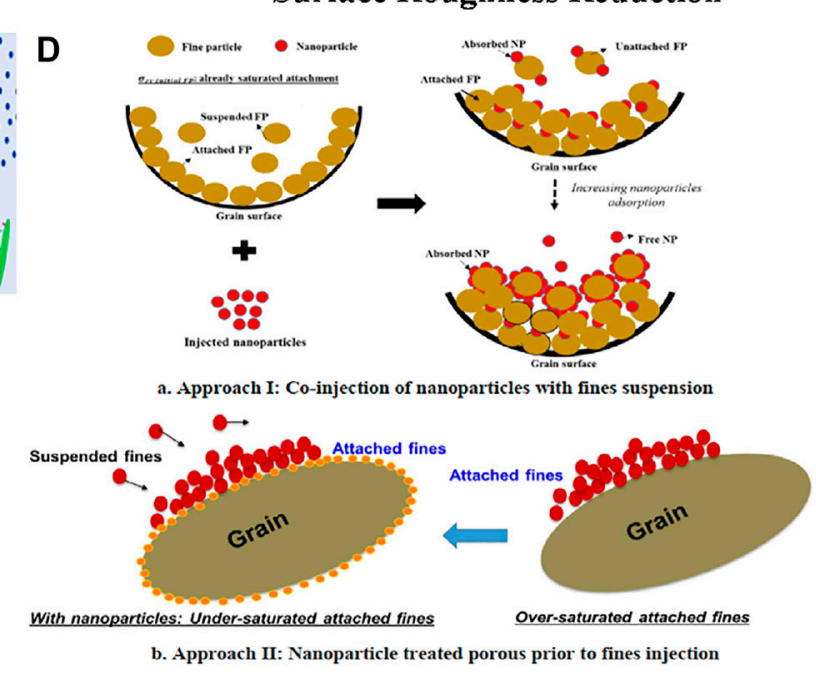

Fine Migration Mitigation

Suppress of Clay Swelling

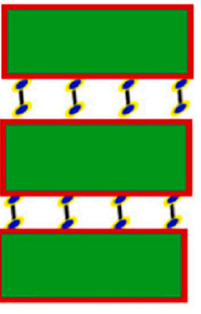

$\mathrm{PNSC}+\mathrm{NH}_{2}$ as clay swelling Inhibitor

\section{Reduce injection pressure and augment water injection}<smiles>[CH]C1CC1</smiles>

NP Property

(Size, surface modification, shape,

NP mixture)

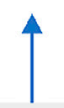

Solution Property

(Ionic strength, $\mathrm{pH}$, temperature, additives)

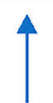

Technical Parameters

(Permeability, pore size, rock type, rock surface charge heterogeneity, rock surface roughness)

FIGURE 1 | NPs as depressurization and augmented injection agents: functional mechanisms and influential factors. Sources: Yan et al. (2017), Shen et al. (2021), Oseh et al. (2020), Zhao et al. (2017), Zhao et al. (2021), Yuan et al. (2018). (A) Slip effect, (B) Surface roughness reduction, (C) Suppress of clay swelling, (D) Fine migration mitigation. 
drag reduction effect which is beneficial to induce a larger pressure drop. In Wuqi Oilfield, polysilicon adsorption decreased the thickness of water film, and the effective porosity increased from 22.22 to 37.14\% (Qi, 2014). Moreover, acidification pretreatment is conducive to NPs performance, with which effective water permeability increases by $458.3 \%$, comparing to that of $160.0 \%$ without pretreatment (Liu et al., 2019).

Clay Swell Suppression: The volume of clay minerals could increase by up to 20 times when water layers are inserted, leading to decreased pore/throat size and increased water injection pressure especially in tight and low permeability reservoirs (Amorim et al., 2007). Hu et al. (2020) indicated that with a clay anti-swelling rate of $42.0 \%$, the subsequent water injection pressure in tight sandstone reduced by $23.0 \%$. By forming a water-resisting layer or narrowing down the interspaces between clay platelets, adsorbed NPs can reduce the clay swelling index by 1.1-3.2 times, comparing to that of $0.42-0.66$ times with potassium chloride solution.

Fine Migration Mitigation: Fine migration during water injection causes permeability impairment and poses a great threat to the subsequent water injection. NPs with high surfaces areas can easily adsorb on migrating fines or rocks. $\mathrm{NP}$ on migrating fines reduces the repulsive forces between modified fines and rocks, while NP on rocks decreases surfaces energy, enhances heterogeneities and increases the adhesion forces. Yuan et al. (2018) indicated that NPs adsorb on pore surfaces is better preferred to control fine migration than NPs adsorb on migrating fines. Zhao et al. (2021) found that the fine control efficiency of $\mathrm{Al} 2 \mathrm{O} 3$-treated porous media was over $60 \%$, and the injection pressure dropped by $33.3 \%$ at an ionic strength (IS) of $500 \mathrm{mmol} / \mathrm{L}$.

Surface Roughness Reduction: Rock surface roughness has a significant impact on phase distribution and fluid flow pattern (Cousins et al., 2018; Yi et al., 2019). Generally, an increase in rock surface roughness increases two-phase interference and flow resistance. By occupying the spaces between sands, NP adsorption can effectively decrease rock roughness and thickness of water film, therefore, to reduce the flow resistance and augment water injection. With a NP concentration of $0.15 \mathrm{wt}$ $\%$, the surface roughness reduced by $16.67 \%$ and the pressure decreased by around $17.0 \%$ (Zhao et al., 2017).

\section{INFLUENCIAL FACTORS}

NPs performance as depressurization and augmented injection agents highly depends on their retention in porous media, and any factors that affect NP transportation and adsorption behaviors would have an impact. Possible influential factors may include,

NP Properties: NP properties influences the rock-NP interactions and impose impacts on NP transportation and retention. He et al. (2019) found that NP retention in saturated porous media increased with decreasing NP concentration and increasing NP size, but Wang et al. (2012) and O'Carroll et al. (2013) believed that the more intensive
Brownian movement and higher collision probability of smaller particles might reduce the trap possibility. In addition, when different NPs are mixed, behaviors may change. For instance, $\mathrm{TiO}_{2}$ could significantly increase GO retention at varying $\mathrm{NaCl}$ and $\mathrm{CaCl}_{2}$ cases (Zhang et al., 2017; Xia et al., 2019).

Solution Properties: NP stability has a close relationship with NP mobility. In general, more NPs could be recovered with higher repulsion between NPs and rocks. An increase in IS will promote particle aggregation and weaken the repulsion, thereafter, result in a considerable reduction of recovered NPs. For example, $\mathrm{TiO}_{2}$ recovery rates in distilled water, $500 \mathrm{mM} \mathrm{NaCl}$ and $10 \mathrm{mM} \mathrm{MgCl}_{2}$ were $72.2 \%, 17.6$ and $26.1 \%$, respectively. Changes in solution $\mathrm{pH}$ also has similar impacts. The impacts of temperature are IS-dependent, but NPs retention generally increases at higher temperatures (Bayat et al., 2014).

Reservoir Properties: NPs are selective to reservoir permeability. If the permeability is too high, NP adsorption may show a noticeable decrease. While when the permeability is too low, NPs may hardly enter into the narrow pores to take effect. When particle size $(\mathrm{d})$ is larger than 0.59 times of the pore throat size (D), pore throat clogging would occur, when $\mathrm{d}<0.59$ $\mathrm{D}$, individual particle would easily pass through the pores and possibly deposit on rock surfaces. When $d$ is far smaller than $D$, for example $\mathrm{d} / \mathrm{D}<0.01$, the interactions between particles and porous media can be neglected (Feng et al., 2020). In general, NPs show higher adsorption on heterogeneous tight porous media with opposite charge. For instance, $\mathrm{SiO}_{2} \mathrm{NPs}$ tend to adsorb on limestone instead of sandstone, while $\mathrm{TiO}_{2}$ NPs prefer to adsorb on sandstone rather than on limestone. In Yu's case ( $\mathrm{Yu}$ et al., 2012), NPs recovered from $33 \mathrm{mD}$ sandstone, $57.6 \mathrm{mD}$ sandstone and $132 \mathrm{mD}$ limestone $5.29 \mathrm{mD}$ dolomite were $23.0 \%, 86.0$ and $32.6 \%$, respectively. The influences of rock surface roughness are still controversial. Bayat et al. (2014) believed that NPs may easily trapped by irregular dents and bumps, but Zhou et al. (2021) and Suri et al. (2020) suggested that the increases in energy loss, turbulence might promote NP migration in facture center rather than deposition in grooves.

Technological Parameters: Increases in NP dosage and injection volume give different results. Phenrat et al. (2009) found the impacts of NP dosage were negligible, Feng et al. (2020) stated NP retention increased, and Sun et al. (2015) reported increased NP mobility thanks to the faster occupation of attachment sites. A rise in flow rate also demonstrates different impacts, either accelerate the particle bridging or wash away the reversibly and loosely attached NPs.

\section{POTENTIAL RISKS AND POSSIBLE SOLUTIONS}

The potential of NPs as depressurization and augmented injection agents is huge, but there are also some risks confronted with this treatment. Such as,

Pore Plugging: NP adsorption not only produces slip effects, but also narrows the flowing channels. NP blocking takes place when NP diameter is larger than the size of pore throats or when NP aggregation/bridging occurs. The performance of NP 
formulas highly depends on the net effects and the change in effective permeability. Synthesis of smaller NPs such as silicon dots and caron dots (Rao et al., 2018; Zhou et al., 2020) may be a feasible solution.

Involvement of Organic Solvents: Hydrophobic NPs demonstrate excellent pressure reduction capability by generating slip effect. However, NPs alone can hardly be dispersed in water if no other additives are introduced, so organic solvents are required. The usage of organic solvents not only increases the cost, but also leads to environmental pollution. Two possible methods to reduce the risks are 1) apply dispersants, such as surfactants, 2) develop Janus, responsive and amphiphilic NPs.

Conditions Applicable: Limited by NP stability or severe NP aggregation/retention, Feng et al. (2020) claimed that the calcium and magnesium ions in injection water should be no higher than $300 \mathrm{mg} / \mathrm{L}$. Given the fact that many oilfields worldwide are featured by high temperature and high salinity with huge amounts of multivalent cations, developing NPs with good salt and temperature tolerance is of crucial importance. To cater for the requirements of high salinity and high temperature conditions, endow NPs with steric repulsion is the key, verified NP surface modifiers are zwitterionic polyelectrolyte, copolymers, highly soluble silanes, etc.

Material Cost and Safety: At the present stage, the investment for NP manipulation and fabrication is relatively high than conventional materials, therefore, increasing NP performance is necessary and important to reduce the required dosage and the cost. In addition, the adverse impacts of NPs on human beings as well as the environment are still unclear. From the perspective of diffusivity, we highly suggest using NP dispersion instead of NP powder in daily experiment to minimize the risks. A comprehensive study concerning NP safety is required and a

\section{REFERENCES}

Al-Harbi, M. S., Al-Dhafeeri, A. M., Al-Rufaie, Y. A., and Mohammed, S. K. (2006). "Evaluation of Acid Treatment Results for Water-Injection wells in Saudi Arabia," in SPE Annual Technical Conference and Exhibition, Paper SPE101344-MS. doi:10.2118/101344-MS

Amorim, C. L. G., Lopes, R. T., Barroso, R. C., Queiroz, J. C., Alves, D. B., Perez, C. A., et al. (2007). Effect of clay-water Interactions on clay Swelling by X-ray Diffraction. Nucl. Instr. Methods Phys. Res. Section A: Acc. Spectrometers, Detectors Associated Equipment 580 (1), 768-770. doi:10.1016/ j.nima.2007.05.103

Bayat, A. E., Junin, R., Ghadikolaei, F. D., and Piroozian, A. (2014). Transport and Aggregation of Al2O3 Nanoparticles through Saturated limestone under High Ionic Strength Conditions: Measurements and Mechanisms. J. Nanopart. Res. 16 (12), 1-12. doi:10.1007/s11051-014-2747-x

Cousins, T. A., Ghanbarian, B., and Daigle, H. (2018). Three-dimensional Lattice Boltzmann Simulations of Single-phase Permeability in Random Fractal Porous media with Rough Pore-Solid Interface. Transp Porous Med. 122 (3), 527-546. doi:10.1007/s11242-017-0938-5

Feng, Q., Cha, L., Dai, C., Zhao, G., and Wang, S. (2020). Effect of Particle Size and Concentration on the Migration Behavior in Porous media by Coupling Computational Fluid Dynamics and Discrete Element Method. Powder Technol. 360, 704-714. doi:10.1016/j.powtec.2019.10.011 well-defined protocol involving materials, engineering, humanity and the environment should be defined.

\section{CONCLUSION}

NPs functioned through different mechanisms including wettability alteration and slip effect, clay swell suppression, fine migration mitigation and surface roughness reduction. A comprehensive understanding of NPs transportation in wellbores and subsurface porous media is essential for successful NP applications, and the performance of NPs for depressurization and augmented injection highly depends on their transportation and retention in complex underground porous media. However, NP applications may confront with the risks of pore plugging, usage of organic solvents, low NP stability, etc. Possible solutions to mitigate these risks are developing novel small, and highly stable responsive/amphiphilic/Janus NPs, construct surfactantNP augmented systems, etc.

\section{AUTHOR CONTRIBUTIONS}

All authors listed have made a substantial, direct, and intellectual contribution to the work and approved it for publication.

\section{FUNDING}

This work was supported by Natural Science Foundation of China (NSFC) (Grant No. 52104019), Scientific Research Development Fund of Yangtze University and Innovation and Entrepreneurship Training program for College Students of Yangtze University (Grant No. Yz2020287).

He, J., Wang, D., and Zhou, D. (2019). Transport and Retention of Silver Nanoparticles in Soil: Effects of Input Concentration, Particle Size and Surface Coating. Sci. Total Environ. 648, 102-108. doi:10.1016/ j.scitotenv.2018.08.136

Hu, C., Zhang, Y., Yang, Z., Zhang, Z., Fan, H., and You, Q. (2020). Experimental Study on Functional Characteristics of $\mathrm{pH}$-Sensitive Nanoparticles for Pressure Reduction and Augmented Injection in Tight Oil Reservoir. J. Mol. Liquids 311, 113253-253. doi:10.1016/j.molliq.2020.113253

Hu, W., Wei, Y., and Bao, J. (2018). Development of the Theory and Technology for Low Permeability Reservoirs in China. Pet. Exploration Develop. 45 (4), 685-697. doi:10.1016/S1876-3804(18)30072-7

Li, X., Feng, Q., Gao, P., Huang, Z., Gong, R., Chen, X., et al. (2021). Application Progress of Nano-SiO $\mathrm{N}_{2}$ in Enhanced Oil Recovery and Depressurization and Injection-Augmenting. Sci. Technol. Eng. 21 (20), 8291-8300.

Liu, P., Niu, L., Tao, X., Li, X., and Zhang, Z. (2019). Hydrophobic Silica with Potential for Water-Injection Augmentation of a Low-Permeability Reservoir: Drag Reduction and Self-Cleaning Ability in Relation to Interfacial Interactions. ACS omega 4 (9), 13681-13686. doi:10.1021/ acsomega.9b00892

O'Carroll, D. M., Liu, X., Mattison, N. T., and Petersen, E. J. (2013). Impact of Diameter on Carbon Nanotube Transport in Sand. J. Colloid Interf. Sci. 390, 96-104. doi:10.1016/j.jcis.2012.09.034

Oseh, J. O., Norddin, M. N. A. M., Muhamad, H. N., Ismail, I., Gbadamosi, A. O., Agi, A., et al. (2020). Influence of (3-Aminopropyl) Triethoxysilane on 
Entrapped Polypropylene at Nanosilica Composite for Shale Swelling and Hydration Inhibition. J. Pet. Sci. Eng. 194, 107560. doi:10.1016/ j.petrol.2020.107560

Phenrat, T., Kim, H.-J., Fagerlund, F., Illangasekare, T., Tilton, R. D., and Lowry, G. V. (2009). Particle Size Distribution, Concentration, and Magnetic Attraction Affect Transport of Polymer-Modified $\mathrm{Fe} 0$ Nanoparticles in Sand Columns. Environ. Sci. Technol. 43, 5079-5085. doi:10.1021/es900171v

Qi, C. (2014). Research and Application of Pressure Reducing and Injection Increasing Measures in Wuqi Low Permeability Oilfield. Doctoral dissertation (Xi'an, China: Xi'an Shiyou University).

Qu, H. (2012). Evaluation of Drag-Reducing and Injection-Augmenting Effect of Organic Molecular Membrane Injecting Agent. Adv. Fine Petrochemicals 13 (11), 1-4. doi:10.3969/j.issn.1009-8348.2012.11.001

Rao, Y., Ning, H., Ma, X., Liu, Y., Wang, Y., Liu, H., et al. (2018). Template-free Synthesis of Coral-like Nitrogen-Doped Carbon dots/Ni3S2/Ni Foam Composites as Highly Efficient Electrodes for Water Splitting. Carbon 129, 335-341. doi:10.1016/j.carbon.2017.12.040

Roco, M. C. (2011b). Nanotechnology Research Directions for Societal Needs in 2020: Retrospective and Outlook. Dordrecht, Netherlands: Springer Netherlands.

Roco, M. C. (2011a). The Long View of Nanotechnology Development: The National Nanotechnology Initiative at 10 Years. J. Nanopart. Res. 13 (2), 427-445. doi:10.1007/s11051-010-0192-z

Shen, X., Jiang, G., Li, X., He, Y., Yang, L., Cui, K., et al. (2021). Application of Carboxylated Cellulose Nanocrystals as Eco-Friendly Shale Inhibitors in WaterBased Drilling Fluids. Colloids Surf. A: Physicochemical Eng. Aspects 627, 127182. doi:10.1016/j.colsurfa.2021.127182

Sun, Y., Gao, B., Bradford, S. A., Wu, L., Chen, H., Shi, X., et al. (2015). Transport, Retention, and Size Perturbation of Graphene Oxide in Saturated Porous media: Effects of Input Concentration and Grain Size. Water Res. 68, 24-33. doi:10.1016/j.watres.2014.09.025

Suri, Y., Islam, S. Z., and Hossain, M. (2020). Effect of Fracture Roughness on the Hydrodynamics of Proppant Transport in Hydraulic Fractures. J. Nat. Gas Sci. Eng. 80, 103401. doi:10.1016/j.jngse.2020.103401

Wang, C., Bobba, A. D., Attinti, R., Shen, C., Lazouskaya, V., Wang, L.-P., et al. (2012). Retention and Transport of Silica Nanoparticles in Saturated Porous media: Effect of Concentration and Particle Size. Environ. Sci. Technol. 46, 7151-7158. doi:10.1021/es30031410.1021/es300314n

Wang, T., Zhang, Y., Li, L., Yang, Z., Liu, Y., Fang, J., et al. (2018). Experimental Study on Pressure-Decreasing Performance and Mechanism of Nanoparticles in Low Permeability Reservoir. J. Pet. Sci. Eng. 166, 693-703. doi:10.1016/ j.petrol.2018.03.070

Wang, Z., Cui, M., Wang, X., and Wang, X. (1999). "Investigation and Application of Fracturing and Acidizing Technology to Improve Ultra-deep Well Water Injectivity in DH Oil Field," in SPE Asia Pacific Improved Oil Recovery Conference, Paper SPE-57271-MS. doi:10.2118/57271-MS

Xia, T., Lin, Y., Guo, X., Li, S., Cui, J., Ping, H., et al. (2019). Co-transport of Graphene Oxide and Titanium Dioxide Nanoparticles in Saturated Quartz Sand: Influences of Solution pH and Metal Ions. Environ. Pollut. 251, 723-730. doi:10.1016/j.envpol.2019.05.035
Xu, D., Bai, B., Wu, H., Hou, J., Meng, Z., Sun, R., et al. (2019). Mechanisms of Imbibition Enhanced Oil Recovery in Low Permeability Reservoirs: Effect of IFT Reduction and Wettability Alteration. Fuel 244, 110-119. doi:10.1016/ j.fuel.2019.01.118

Yan, Y.-L., Cui, M.-Y., Jiang, W.-D., He, A.-L., and Liang, C. (2017). Drag Reduction in Reservoir Rock Surface: Hydrophobic Modification by $\mathrm{SiO} 2$ Nanofluids. Appl. Surf. Sci. 396, 1556-1561. doi:10.1016/j.apsusc.2016.11.209

Yi, J., Xing, H., Wang, J., Xia, Z., and Jing, Y. (2019). Pore-scale Study of the Effects of Surface Roughness on Relative Permeability of Rock Fractures Using Lattice Boltzmann Method. Chem. Eng. Sci. 209, 115178. doi:10.1016/j.ces.2019.115178

Yu, J., An, C., Mo, D., Liu, N., and Lee, R. (2012). "Study of Adsorption and Transportation Behavior of Nanoparticles in Three Different Porous media," in SPE Improved Oil Recovery Symposium, Paper SPE-153337-MS. doi:10.2118/ 153337-MS

Yuan, B., Moghanloo, R. G., and Wang, W. (2018). Using Nanofluids to Control Fines Migration for Oil Recovery: Nanofluids Co-injection or Nanofluids Pre-flush? -A Comprehensive Answer. Fuel 215, 474-483. doi:10.1016/j.fuel.2017.11.088

Zhang, M., He, F., Zhao, D., and Hao, X. (2017). Transport of Stabilized Iron Nanoparticles in Porous media: Effects of Surface and Solution Chemistry and Role of Adsorption. J. Hazard. Mater. 322, 284-291. doi:10.1016/ j.jhazmat.2015.12.071

Zhao, M., Wang, S., and Dai, C. (2017). A New Insight into the PressureDecreasing Mechanism of Hydrophobic Silica Nanoparticles Modified by N-Propyltrichlorosilane. J. Surfact Deterg 20 (4), 873-880. doi:10.1007/ s11743-017-1966-4

Zhao, X., Qiu, Z., Gao, J., Ren, X., Li, J., and Huang, W. (2021). Mechanism and Effect of Nanoparticles on Controlling Fines Migration in Unconsolidated sandstone Formations. SPE J. 26, 3819-3831. doi:10.2118/204474-PA

Zhou, Y., Wu, X., Zhong, X., Zhang, S., Pu, H., and Zhao, J. X. (2020). Development of Silicon Quantum Dots Based Nano-Fluid for Enhanced Oil Recovery in Tight Bakken Cores. Fuel 277, 118203. doi:10.1016/j.fuel.2020.118203

Zhou, B., Tang, H., Yin, S., Chen, G., Zhao, F., and Xu, S. (2021). Effect of Fracture Roughness on Transport of Suspended Particles in Fracture during Drilling. J. Pet. Sci. Eng. 207, 109080. doi:10.1016/j.petrol.2021.109080

Conflict of Interest: The authors declare that the research was conducted in the absence of any commercial or financial relationships that could be construed as a potential conflict of interest.

Publisher's Note: All claims expressed in this article are solely those of the authors and do not necessarily represent those of their affiliated organizations, or those of the publisher, the editors and the reviewers. Any product that may be evaluated in this article, or claim that may be made by its manufacturer, is not guaranteed or endorsed by the publisher.

Copyright $\odot 2022$ Chen, Zhong and Xu. This is an open-access article distributed under the terms of the Creative Commons Attribution License (CC BY). The use, distribution or reproduction in other forums is permitted, provided the original author(s) and the copyright owner(s) are credited and that the original publication in this journal is cited, in accordance with accepted academic practice. No use, distribution or reproduction is permitted which does not comply with these terms. 